\title{
TWO-YEAR OPERATION OF THE LIDAR1200: FROM FINE-SCALE TROPOSPHERIC STRUCTURES TO LOWER STRATOSPHERIC WATER VAPOR DETECTION
}

\author{
Hélène Vérèmes $^{(1,2)} *$, Guillaume Payen ${ }^{2}$, Philippe Keckhut ${ }^{3}$, Valentin Duflot ${ }^{(1,2)}$, Jean-Luc Baray ${ }^{4}$, \\ Jean-Pierre Cammas ${ }^{(1,2)}$, Jimmy Leclair de Bellevue ${ }^{1}$, Françoise Posny ${ }^{1}$, Stéphanie Evan ${ }^{1}$, Jean- \\ Marc Metzger $^{2}$, Nicolas Marquestaut ${ }^{2}$, Franck Gabarrot ${ }^{2}$, Susanne Meier ${ }^{5}$, Holger Vömel ${ }^{6}$ and \\ Ruud Dirksen ${ }^{5}$ \\ ${ }^{1}$ Laboratoire de l'Atmosphère et des Cyclones, UMR8105, Saint-Denis de La Réunion, France, \\ *Email: helene.veremes@univ-reunion.fr \\ ${ }^{2}$ Observatoire des Sciences de l'Univers de La Réunion, UMS3365, Saint-Denis de la Réunion, France, \\ ${ }^{3}$ Laboratoire ATmosphères, Milieux, Observations Spatiales-IPSL, UMR8190 CNRS, UVSQ, UPMC, \\ Guyancourt, France, \\ ${ }^{4}$ Laboratoire de Météorologie Physique, UMR6016, Observatoire de Physique du Globe de Clermont- \\ Ferrand, Clermont-Ferrand, France, \\ ${ }^{5}$ Deutscher Wetterdienst, Meteorological Observatory Lindenberg, Lindenberg, Germany, \\ ${ }^{6}$ National Center for Atmospheric Research, Boulder, CO, USA
}

\begin{abstract}
The 2-year lidar water vapor database (November 2013 - October 2015) of the Maïdo Observatory (Reunion Island $/ 21^{\circ} \mathrm{S}, 55.5^{\circ} \mathrm{E}$ ) is now processed. The performances of the lidar in providing accurate vertical structures are shown to be good. The ability to measure quantities of a few ppmv in the lower stratosphere is demonstrated (based on Cryogenic Frost point Hygrometer sonde/lidar profiles comparisons) for a 48-hour integration time period, up to $22 \mathrm{~km}$ (with a vertical resolution of $1.3 \mathrm{~km}$ ).
\end{abstract}

\section{INTRODUCTION}

Since the inauguration of the Maïdo Observatory in October 2012 [1], a Raman lidar system (called "Lidar1200") has been monitoring, several nights a week, water vapor and temperature, from the ground up to the lower stratosphere and in the stratosphere up to the mesosphere, respectively [2].

The calibration methodology of the water vapor Lidar1200 dataset is based on the detection of quasi-stationary periods of the hourly calibration coefficient derived from GNSS observations. The GNSS technique has been chosen in order to improve the reliability of the calibration and the robustness of the water vapor measurement on a long-term perspective. This methodology has been successfully used in the 2013-2015 dataset [3].
The average standard uncertainty in the transfer of the calibration is around $3 \%$. The 2-year database has been processed and a first evaluation of the mean performances has been done, results are presented in the next section.

The Lidar1200 was involved in 5 measurement campaigns at the Maïdo Observatory: MALICCA1 (MAïdo LIdar Calibration CAmpaign) (April 2013) [2][4], MALICCA-2 (November 2013), LIDEOLE-1 (November 2014), MORGANE (Maïdo ObservatoRy Gas and Aerosol NDACC Experiment) (May 2015) and LIDEOLE-2 (September 2015). The field campaigns play an important role in the evaluation of the performances of the Lidar1200. The results of the instrumental comparisons led during the MORGANE campaign illustrate the quality of the Lidar1200 data. The comparison between water vapor lidar profiles and CFH sonde's data are detailed in the next section.

With an average of 1 to 2 measurement night(s) per week and the intensive measurement campaigns, the Lidar1200 will be able to supply regular measurements. The Maïdo Observatory is located in the Southern Hemisphere having tropical and subtropical characteristics (depending on the season). Its data could be used to document various dynamical processes. The analysis of the first 2 years of data of the Lidar1200, detailed in the last sections, led to the characterization of structures that could be detected on the lidar water 
vapor profiles: from fine-scale structures in the troposphere to seasonal variability up to the Upper Troposphere / Lower Stratosphere (UT/LS).

\section{PERFORMANCES OF THE LIDAR1200 IN WATER VAPOR MONITORING}

\subsection{Mean performances}

Mean profiles have been calculated and differentiated into three classes characterized by their integration time: 10, 40 and 240 minutes [3]. The measurement sessions have been averaged and processed with the algorithm used on a routine basis. The mean total uncertainty for the three profiles is lower than $15 \%$ below $9 \mathrm{~km}$ asl regardless of the integration time. The threshold of the total uncertainty of $20 \%$ is reached at 11 , 13 and $16 \mathrm{~km}$ asl for 10-, 40- and 240-min profiles, respectively [3]. Those uncertainties are representative of a mean profile for each integration time, those values should be evaluated case-by-case depending on the measurement conditions (cloud fraction, moon phase...). To reach the tropopause with a weaker uncertainty, it appears important to integrate data on a longer integration time period than 4 hours (which represents a typical night of measurement at the Maïdo Observatory under good meteorological conditions).

\subsection{Performances in the UT/LS}

A 9-hour session has been operated in September 2015. The profiles reached $16 \mathrm{~km}$ with an uncertainty of $\sim 35 \%$ [3]. To cross the tropopause with an uncertainty lower than $20 \%$, several nights of measurement are necessary. The profiles of each campaign (integrating 12 to 48 hours) demonstrated that at least 10 hours of integration are necessary to reach the lower stratosphere [3]. To increase the upper limit of the profiles of only $1 \mathrm{~km}$, it requires twice or three times that value. A threshold of 48 hours (MORGANE campaign) has been identified to find a significant improvement of the performances; the water vapor mixing ratio is retrieved up to $22 \mathrm{~km}$ with an uncertainty lower than 0.8 ppmv / $22 \%$ and with a vertical resolution of $1.3 \mathrm{~km}$ [3].

\subsection{Validation: comparison with CFH sonde's data}

$5 \mathrm{CFH}$ sondes were launched simultaneously with Lidar1200 measurements. The water vapor mixing ratio profiles from both techniques were compared [3]. When taking the $\mathrm{CFH}$ measurements as a reference, the results led to the validation of the Lidar1200 profiles between 2.2 and $22 \mathrm{~km}$ asl and to the establishment of integration time criteria (depending on the altitude and the thickness of the observed water vapor structures). The average biases between the CFH and the Lidar1200 data in the lower and middle troposphere, in the upper troposphere and in the lower stratosphere (Fig. 1) were lower than $12 \%$ [3]. The CFH and the Lidar1200 are in agreement up to the lower stratosphere $(22 \mathrm{~km}$ asl), with respect to their uncertainties. This agreement validates the data processing scheme of the Lidar1200. The first results between the $\mathrm{CFH}$ and the Lidar 1200 profiles (MORGANE campaign) shows that the instruments disagree above $22 \mathrm{~km}$ asl [3]. It will be further investigated through future measurement campaigns.

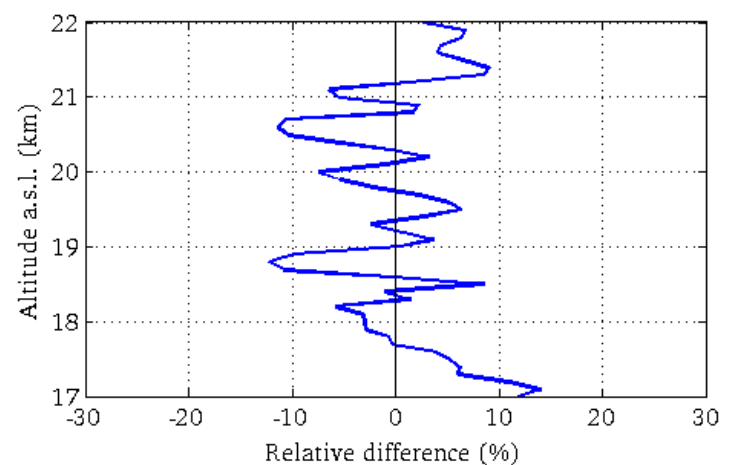

Figure 1 Difference between the lidar (integration of all the data) and the mean CFH water vapor mixing ratio profiles of the MORGANE campaign between 17 and $22 \mathrm{~km}$ asl (CFH data are taken as reference)

\section{DETECTION OF FINE-SCALE STRUC- TURES IN THE TROPOSPHERE}

Comparisons with the $\mathrm{CFH}$ radiosoundings of the field campaigns show that the Lidar 1200 was able to detect a structure of 100-m thick with a time step of 5 minutes at $9 \mathrm{~km}$ asl [3]. The Lidar 1200 is able to detect and monitor tropospheric water vapor structures of a few hundred meters and a small lifetime up to the middle troposphere. 


\section{PRELIMINARY CHARACTERIZATION OF SEASONAL VARIATIONS OF WATER VAPOR}

\subsection{Seasonal cycle over Reunion Island}

The analysis of monthly profiles extracted from the Lidar1200 dataset (between November 2013 and October 2015) illustrates the ability of the lidar to characterize the seasonal variability of the water vapor [3]. The monthly profile corresponds to the integration of the data of one month with the same calibration coefficient, which represents 8 to 48 hours of measurements. The temporal series shows a clear seasonal cycle from the ground up to the middle troposphere. Some variability appears in the upper troposphere and in the lower stratosphere but no seasonal cycle could be characterized. The vertical range of this seasonal cycle and the amplitude of the water vapor variability between summer and winter from those preliminary results [3] are different from the first water vapor climatology established in 2012 on a previous configuration of the system [5]. The improvement of the system and the data processing and the specific calibration methodology benefited the characterization of the seasonal cycle of water vapor in the South-West Indian Ocean.

\subsection{Signatures of water vapor transport}

Seasonal profiles were calculated from the monthly profiles: the 3 monthly profiles of each season were averaged. Their analysis illustrates

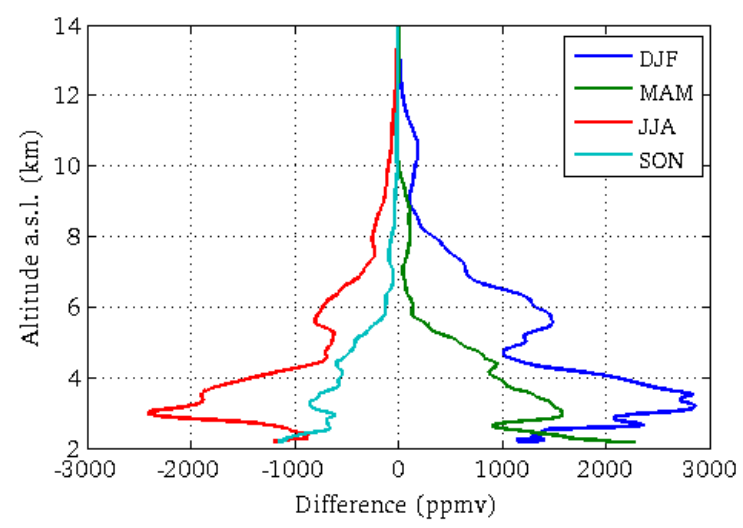

Figure 2 Difference between seasonal and the total mean water vapor mixing ratio profiles (summer in blue, autumn in green, winter in red and spring in cyan) [data: quasi-stationary periods / Lidar1200] the ability of the lidar to detect signatures of water vapor transport. In the lower troposphere, the vertical structure of the humidity field associated with the trade winds inversion (relative maximum at the basis and relative minimum at the top of the inversion layer) is detailed, as its thickening during the austral summer, in Figure 2. It documents the role of the cumulus clouds in the moistening of the upper part of the trade winds layer. The results show the detection in altitude of the humid air flux in the middle troposphere, convected by the general Hadley circulation, around $10-11 \mathrm{~km}$ in austral summer and $8-9 \mathrm{~km}$ in austral autumn (Fig. 2).

\section{CONCLUSIONS}

The Lidar1200 is able to provide high-resolution (vertical and temporal) water vapor profiles in the troposphere on a routine basis. This system is able to reach the lower stratosphere and to detect water vapor mixing ratios of only a few ppmv. A rigorous work on the design of the system and on the evaluation of the data has been carried out on the instrument in order to meet the definition of « a reference observation » [6]. This lidar is dedicated to provide regular water vapor measurements to international networks such as NDACC (Network for the Detection of Atmospheric Composition Change) and GRUAN (GCOS Reference Upper Air Network).

A user's guide for the time of integration of the data has been defined empirically thanks to the results of the instrumental comparisons [3] and is based on a compromise between the vertical resolution and the uncertainty. The detection of structures of a few hundred meters can be realized with 10-min integration files (with a vertical resolution lower than $100 \mathrm{~m}$ ). 40 minutes are necessary to realize instrumental comparisons in the troposphere. To reach the upper troposphere, an integration time of 4 hours should be covered. Around 10 hours of integration are required to cross the tropopause with a vertical resolution of about $1.3 \mathrm{~km}$.

The exploitation of the Lidar1200 database on its own and with others measurements of the Maïdo Observatory will bring new results on the characterization of the tropospheric water vapor variability, the monitoring of the water vapor in lower stratosphere, the study of stratosphere- 
troposphere exchanges [7] and the validation of satellite measurements.

\section{ACKNOWLEDGEMENTS}

The lidar data used in this publication were obtained as part of the Network for the Detection of Atmospheric Composition Change (NDACC) and a level 2 product as daily vertical water vapor profiles will be publicly available through the NDACC portal and the French atmospheric data portal. The raw data and other products will be available on demand and available at the OPAR web portal. We acknowledge the ACTRIS project and the support of the European Community (Research Infrastructure Action under the FP7 "Capacities" specific program for Integrating Activities, ACTRIS Grant Agreement no. 262254). Acknowledgements are addressed to the European Commission (FEDER program), Région Réunion and CNRS for their strong support in the building of the Maïdo facility. Acknowledgements are also addressed to the Université de $\mathrm{La}$ Réunion and CNRS for their strong support of the OPAR station and the OSU-R activities. The research leading to these results was supported by the French LEFE INSU-CNRS Program (VAPEURDO and VEGA projects). The authors gratefully acknowledge E. Golubic, P. Hernandez and L. Mottet, Y. Courcoux, J. Porteneuve, A. Hauchecorne and D. Dionisi.

\section{References}

[1] Baray et al., 2013: Maïdo observatory: a new high-altitude station facility at Reunion Island $\left(21^{\circ} \mathrm{S}, \quad 55^{\circ} \mathrm{E}\right)$ for long-term atmospheric remote sensing and in-situ measurements, Atmos. Meas. Tech., 6, 2865-2877.

[2] Dionisi et al., 2015: Water vapor observations up to the lower stratosphere through the Raman lidar during the Maïdo Lidar Calibration Campaign, Atmos. Meas. Tech., 8, 1425-1445.

[3] Vérèmes et al., 2017: A Raman lidar at Maïdo Observatory (Reunion Island) to measure the water vapor in the troposphere and in the lower stratosphere: calibration and validation, Atmos. Meas. Tech. Discuss., in review.

[4] Keckhut et al., 2015: Introduction to the MALICCA campaign dedicated to the validation of Upper Air Meteorological parameters, J. Appl. Remote Sens, 9(1), 094099.

[5] Hoareau et al., 2012: A Raman lidar at La Reunion $\left(20.8^{\circ} \mathrm{S}, 55.5^{\circ} \mathrm{E}\right)$ for monitoring water vapour and cirrus distributions in the subtropical upper troposphere : preliminary analyses and description of the future system, Atmos. Meas. Tech., 5(6), 13331348.

[6] Immler et al., 2010: Reference Quality Upper-Air Measurements: guidance for developing GRUAN data products, Atmos. Meas. Tech., 3 (5), 1217-1231.

[7] Vérèmes et al., 2016: Multiple subtropical stratospheric intrusions over Reunion Island: Observational, Lagrangian, and Eulerian numerical modeling approaches, $J$. Geophys. Res. Atmos., 121, 14,414-14,432. 